\title{
IDENTIFIKASI DAN ANALISIS KADAR FLAVONOID \\ EKSTRAK GETAH ANGSANA (Pterocarpus indicus Willd) \\ DI DUSUN WANATH KECAMATAN LEIHITU KABUPATEN MALUKU TENGAH
}

\author{
Nurmila $^{1}$, H. Sinay ${ }^{2}$, Theopilus Watuguly ${ }^{2}$ \\ ${ }^{1}$ Alumni Program Studi Pendidikan Biologi FKIP Universitas Pattimura \\ ${ }^{2}$ Program Studi Pendidikan Biologi FKIP Universitas Pattimura \\ Email: milanur0297@gmail.com
}

\begin{abstract}
Background: Medicinal plants have many benefits that make it a traditional medicine for society. One of the medicinal plants used by the community, especially the Wanath Hamlet community, is the angsana gum (Pterocarpus indicus Willd.) In treating diseases.

Method: This study aims to identify and analyze flavonoid levels in angsana sap (Pterocarpus indicus Willd.) In Wanath Hamlet qualitatively (flavonoid color test) and quantitative (flavonoid content analysis).

Results: The results show a change in color to yellow which indicates that the sap is positive for flavonoids, while in aquades it shows clear color changes which indicate negative.

Conclusion: Qualitative test (color test) of angsana gum extract positively contains flavonoids when identified with several flavonoid reagents which produce yellow.
\end{abstract}

Keywords: Identification, flavonoids, angsana gum (Pterocarpus indicus Willd.)

\begin{abstract}
Abstrak
Latar Belakang: Tumbuhan obat memiliki banyak khasiat yang menjadikannya sebagai obat tradisional masyarakat. Salah satu tumbuhan obat yang dimanfaatkan masyarakat khususnya masyarakat Dusun Wanath yaitu getah angsana (Pterocarpus indicus Willd.) dalam mengobati penyakit.

Metode: Penilitian ini bertujuan untuk mengidentifikasi dan menganalisis kadar flavonoid pada getah angsana (Pterocarpus indicus Willd.) di Dusun Wanath secara kualitatif (uji warna flavonoid) dan kuantitatif (analisis kadar flavonoid).

Hasil: Hasil menunjukan perubahan warna menjadi kuning yang menandakan bahwa getah tersebut positif terdapat flavonoid, sedangkan pada aquades menunjukan perubahan warna menjadi jernih yang menandakan negatif.

Kesimpulan: Uji kualitatif (uji warna) ekstrak getah angsana positif mengandung flavonoid ketika diidentifikasi dengan beberapa pereaksi flavonoid yaitu menghasilkan warna kuning.
\end{abstract}

Kata Kunci: Identifikasi, flavonoid, getah angsana (Pterocarpus indicus Willd.) 


\section{PENDAHULUAN}

Indonesia merupakan salah satu negara dengan kekayaan hayati terbesar yang memiliki lebih dari 30.000 spesies tanaman tingkat tinggi. Hingga saat ini, tercatat 7000 spesies tanaman yang telah diketahui khasiatnya, namun hanya kurang dari 300 tanaman yang telah digunakan sebagai bahan baku industri farmasi secara regular. Tumbuhan obat merupakan yang salah satu atau seluruh bagian pada tumbuhan tersebut mengandung zat aktif yang berkhasiat bagi kesehatan yang dapat dimanfaatkan sebagai penyembuh penyakit (Dalimatra, 2000; Wijayakusuma, 2008). Tumbuhan obat di Indonesia biasanya digunakan untuk meningkatkan kesehatan (promotif), memulihkan kesehatan (rehabilitatif), pencegahan penyakit (preventif), dan penyembuhan (kuratif). Namun eksitensinya belum dapat disertakan dengan pelayanan pengobatan modern dengan menggunakan obat kimia, karena belum sepenuhnya teruji keamanan dan manfaatnya (BPOM, 2006).

Masyarakat Indonesia masih sangat tergantung pada tumbuhan obat yang dipercaya dapat mengobati penyakit. Kepercayan ini disebabkan oleh beberapa faktor yaitu tumbuhan obat mudah didapat, resep secara turun temurun, tidak membutuhkan banyak biaya, pengalaman, dan perkiraan semata. Meskipun belum teruji keamanan manfaatnya dan kandungannya secara medis. Karena kepercayaan tersebut masyarakat Indonesia khususnya masyarakat yang tinggal di desa memiliki cara tersendiri untuk memanfaatkan tumbuhan sebagai obat, biasanya dengan cara mengonsumsinya secara langsung atau berupa simplisia baik berupa akar, batang, getah, kulit, daun, bunga, buah, serta biji.

Sebagaimana halnya masyarakat di Dusun Wanath Kecamatan Leihitu Kabupaten Maluku Tengah. Di Dusun ini, masyarakatnya masih menggunakan tumbuhan obat dalam pengobatan tradisional. Salah satu jenis tumbuhan yang sering digunakan dalam pengobatan tradisional yaitu tumbuhan angsana (Pterocarpus indicus Willd.). Angsana merupakan jenis tanaman pohon berumah dua (deciduous) yang tumbuh dengan ketinggian 30-40 meter dengan diameter batang hingga lebih dari 2 meter. Angsana memiliki organ yang terdiri atas akar, batang, daun, bunga, buah dan biji. Batang yang luka mengeluarkan eksudat merah gelap yang disebut "kino" atau Getah.

Getah inilah yang selalu di manfaatkan dalam pengobatan tradisional. Jenis penyakit yang sering diobati dengan getah angsana ini adalah penyakit sariawan. Adanya kemampuan getah angsana untuk memyebuhkan penyakit, diduga disebabkan karena pada getah angsana terdapat atau terkandung senyawa aktif tertentu yang memiliki kemampuan untuk menyembuhkan penyakit seperti sariawan. Salah satu senyawa aktif yang memliki kemampuan untuk menyembuhkan penyakit yaitu flavonoid. Manfaat flavonoid antara lain untuk melindungi struktur sel, meningkatkan efektivitas vitamin C, antiinflamasi, mencegah keropos tulang dan sebagai antibiotik (Haris, 2011).

Flavonoid merupakan salah satu senyawa bahan alam yang paling banyak ditemukan di dalam jaringan tanaman (Rajalakshmi, 1985 dalam Redha, 2010). Sejumlah tanaman obat yang mengandung flavanoid di laporkan telah memiliki aktivitas antioksidan, antibakteri, antivirus, antiradang, antielergi dan antikanker (Kurniasari, 2006). Walaupun sudah digunakan sebagai bahan alami dalam pengobatan tradisional oleh masyarakat Dusun Wanath, namun belum diketahui kandungan bahan aktif flavonoid yang terdapat dalam getah angsana tersebut dan berapa besar kadarnya.

\section{MATERI DAN METODE}

Tipe penelitian yang digunakan dalam penelitian ini adalah penelitian eksperimen. Lokasi penelitian yaitu pengambilan getah angsana di Dusun Wanath dan identifikasi dan analisis flavonoid dilakukan di Laboratorium Kimia Dasar FMIPA Universitas Pattimura pada tanggal 01-08 November. Objek penelitian adalah getah angsana dari Dusun Wanath yang diambil sebanyak $120 \mathrm{ml}$. Variabel dalam penelitian adalah kadar flavonoid pada getah angsana. Alat yang digunakan aluminium foil, botol selai, cawan petri, chamber, corong pisah, gelas kimia, hot plate, kertas label, kamera, kertas saring, mortal dan 
pastle(alue), neraca analitik, pipet tetes, pisau besar, rak tabung reaksi, rotary evaporator, spektofotometer UV-Vis, sendok, tabung reaksi, thermometer. Bahan yang digunakan getah angsana, methanol, aquades, asam asetat glacial, $\mathrm{NaOH}, \mathrm{AlCl}_{3}$, $\mathrm{NH}_{4} \mathrm{OH}$, kuersetin.

\section{Tahap Persiapan Sampel}

a. Getah angsana akan di ambil pada waktu pagi hari dengan menggunakan pisau besar,sendok, dan botol selai yang sudah dibersihkan.

b. Pengambilan getah angsana dengan cara menoreh atau melukai batang pohon sebesar $6 \mathrm{~cm}$ pada 3 batang pohon.

c. Getah yang keluar akan diambil dengan sendok dan dimasukan ke dalam botol selai sebanyak $120 \mathrm{ml}$.

d. Setelah itu getah angsana di bawah ke laboratorium untuk diidentifikasi dan dianalis flavonoidnya.

\section{Tahap Pelaksanan}

\section{Pembuatan Ekstrak}

Pembuatan ekstrak getah angsana dilakukan dengan metode maserasi (Sani, dkk. 2014).

1) Getah yang telah dikumpulkan kemudian dituangkan ke dalam cawan petri, setelah itu diagin-anginkan di dalam runagan.

2) Getah yang sudah kering kemudian dihaluskan dengan mortal dan pastle (alue).

3) Timbang bubuk getah angsana sebanyak 25 gram, kemudian dimaserasi selama 3 kali dalam 24 jam

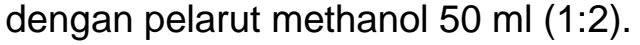

4) Filtrat yang diperoleh diuapkan dengan rotary evaporator sampai diperoleh ekstrak kental methanol.

5) Ekstrak kental tersebut diencerkan dengan sedikit methanol kemudian diaduk sampai encer dan homogen.

6) Kemudian lakukan penyaringan dengan menggunakan corong pemisah.

\section{Uji Kualitatif Flavonoid}

Uji kualitatif flavonoid yang digunakan yaitu dengan menggunakan metode mikrokimiawi (Mulyani dan Laksana, 2011).

1) Getah angsana yang sudah diekstraksi kemudian dimasukan pada tabung reaksi kemudian identifikasi dengan pereaksi dan tanpa pereaksi.

a) Tanpa pereaksi: diletakkan pada tabung reaksi kemudian diberi aquades dengan perbandingan yang sama.

b) Dengan pereaksi: diletakkan pada masing-masing tabung reaksi kemudian diberi pereaksi identifikasi $\mathrm{NaOH}, \mathrm{AlCl}_{3}$, dan $\mathrm{NH}_{4} \mathrm{OH}$ dengan perbandingan yang sama.

2) Amati peruahan warna yang terjadi pada ekstrak getah angsana.

3) Perubahan warna yang diperoleh dibandingkan antara sebelum dan sesudah diberi pereaksi, dan dilihat perubahan warna yang terjadi.

4) Apabila terbentuk warna kuning menunjukkan adanya flavonoid.

\section{Uji Kuantitatif Flavonoid}

Uji kuantitatif yang dilakukan adalah dengan penentuan kandungan kadar flavonoid total pada ekstrak getah angsana.

\section{Pembuatan larutan standar kuersertin}

Ditimbang sebanyak $25 \mathrm{mg}$ baku standar kuersetin dan dilarutkan dalam 25 $\mathrm{mL}$ methanol. Larutan stok dipipet sebanyak $1 \mathrm{~mL}$ dan dicukupkan volumenya sampai $10 \mathrm{~mL}$ dengan methanol untuk 1000 ppm. Dipipet kembali $5 \mathrm{~mL}$ kemudian dicukupkan volumenya sampai $50 \mathrm{~mL}$ dengan methanol. Dari larutan standar kuesertin 100 ppm, kemudian dibuat beberapa konsentrasi yaitu 2 ppm, 4 ppm, 6 ppm, 8 ppm, dan 10 ppm. Dari masingmasing konsentrasi larutan standar kuersetin ditambahkan $3 \mathrm{~mL}$ methanol, 0,2 $\mathrm{mL}$ AICl3, 0,2 $\mathrm{mL}$ asam asetat glacial, dan $5,6 \mathrm{~mL}$ aquades. Setelah itu diinkubasi selama 30 menit dan diukur absorbansinya pada spektofotometer UV-Visible dengan panjang gelombang $370 \mathrm{~nm}$.

\section{Pembuatan Larutan Sampel}

Kandungan flavonoid total merujuk pada prosedur Chang et al., (2000) dengan beberapa konsentrasi menggunakan kuersetin sebagai standar. Ditimbang ekstrak metanolik getah angsana sebanyak $25 \mathrm{mg}$ dan dilarutkan dalam $25 \mathrm{~mL}$ methanol.Dari larutan stok dipipet sebanyak $1 \mathrm{~mL}$ dan dicukupkan volumenya sampai 10 $\mathrm{mL}$ dengan methanol. Kemudian dipipet 1 $\mathrm{mL}$ dan ditambahkan $3 \mathrm{~mL}$ methanol, 0,2 
$\mathrm{AlCl}_{3}, 0,2 \mathrm{~mL}$ asam asetat glasial, dan 5,6 $\mathrm{mL}$ aquades. Setelah itu diinkubasi selama 30 menit dan diukur absorbansinya pada spektofotometer UV-Visible dengan panjang gelombang $370 \mathrm{~nm}$.

\section{Analisis Kandungan Flavonoid Menggunakan Spektofotometer}

Sampel akan dianalisis kandungan flavonoidnya dengan cara menambahkan pelarut methanol dan larutan $\mathrm{AlCl} 3$ kemudian dimasukan kedalam chamber, amati perubahan yang terjadi dibawah sinar UV-Visible $370 \mathrm{~nm}$ dan lihat panjang gelombang atau frekuensi lawan intensitas serapan (absorbansi) yang menunjukan hasil analisis flavonoid pada penggunaan spektofotometer UV-Visible.

Menurut Neldawati (2013) untuk menentukan kadar flavonoid berdasarkan nilai absorbansi yang didapat dengan menggunakan rumus berikut:

$$
Y=a x+b
$$

Dengan:

$$
\begin{array}{ll}
\mathrm{Y} & =\text { nilai absorbansi } \\
\mathrm{X} & =\text { kadar flavonoid } \\
\mathrm{a}, \mathrm{b} & =\text { konsentrasi }
\end{array}
$$

\section{HASIL DAN PEMBAHASAN}

Hasil identifikasi flavonoid pada getah batang angsana dilakukan secara kualitatif dengan menggunakan metode mikrokimiawi. Untuk melihat perubahan warna pada berbagai pereaksi yang sudah ditentukan, sehingga dapat mengidentifikasi flavonoid pada getah angsana. Hasil identifikasi kualitatif flavonoid disajikan dalam tabel 1.

\section{Tabel 1. Hasil Identifikasi Kualitatif Flavonoid Ekstrak Getah Angsana}

\begin{tabular}{cccccc} 
No & Warna awal & Pereaksi & Perubahan Warna & Gambar Perubahan & Hasil Uji \\
\hline 1 & Merah & Kontrol & Larutan jernih & \\
2 & Merah & $\mathrm{NH}_{4} \mathrm{OH}$ & Kuning & & - \\
3 & Merah & $\mathrm{NaOH}$ & Kuning & & + \\
4 & Merah & $\mathrm{AlCl}_{3}$ & Kuning & & + \\
\hline
\end{tabular}

Keterangan: - : Negatif (tidak terdapat flavonoid); + : Positif (terdapat flavonoid.

Uji Kuantitatif Flavonoid Getah Angsana

Uji kuantitatif flavonoid getah angsana untuk menentukan kadar flavonoid pada ekstrak getah angsana. Kurva standar adalah kurva yang dibuat berdasarkan konsentrasi standar dan nilai absorbansi standar. Kurva larutan standar kuersetin diperoleh dengan mengukur absorbansi dari larutan standar kuersetin, pada berbagai konsentrasi panjang gelombang maksimum yang telah ditentukan sebelumnya yaitu 370 $\mathrm{nm}$. Data larutan standar dan absorbansi dapat dilihat pada tabel 2 sebagai berikut.
Tabel 2. Absorbansi Larutan Standar Kuersetin.

\begin{tabular}{ccc}
\hline No & Konsentrasi (mg/ltr) & Absorbansi \\
\hline 1 & 2 & 0,116 \\
2 & 4 & 0,221 \\
3 & 6 & 0,324 \\
4 & 8 & 0,433 \\
5 & 10 & 0,535 \\
\hline
\end{tabular}


Setelah diperoleh absorbansi dari larutan standar, data diolah menjadi grafik antara konsentrasi larutan standar kuersetin dengan absorbansi.

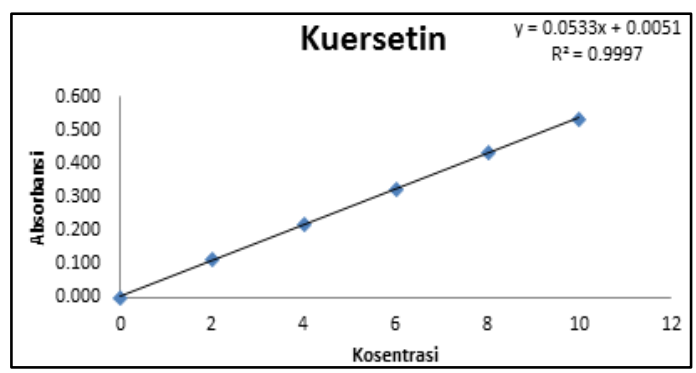

Gambar 1. Kurva Konsentrasi Standar
Kuersetin dan Absorbansi
Standar.
Hasil pengukuran absorbansi larutan standar pada berbagai konsentrasi ditampilkan kurva kalibras menunjukan adanya hubungan yang linear antara absorbansi dengan konsentrasi yang terlihat pada pengukuran linearitas sebesar 0.9997.

Besarnya angka linearitas mendekati nilai satu sehingga dapat dikatakan bahwa absorbansi merupakan fungsi yang besarnya berbanding lurus dengan konsentrasi. Jadi, semakin besar konsentrasi maka semakin besar pula nilai absorbansinya.

Tabel 3. Hasil Analisis Kadar Flavonoid Pada Ekstrak Getah Angsana

\begin{tabular}{ccccccc}
\hline No & Ulangan & $\begin{array}{c}\text { Berat } \\
\text { Sampel } \\
(\mathbf{g r})\end{array}$ & Absorbansi & $\begin{array}{c}\text { Kosentrasi } \\
(\mathbf{m g})\end{array}$ & $\begin{array}{c}\text { Kadar } \\
\text { Flavonoid (\%) }\end{array}$ & $\begin{array}{c}\text { Rata-rata } \\
\text { Kadar } \\
\text { Flavonoid (\%) }\end{array}$ \\
\hline 1 & I & 10,0121 & 0,231 & 4,3 & 0,0429 & 0,0434 \\
2 & II & 10,0214 & 0,237 & 4,4 & 0,0439 & \\
\hline
\end{tabular}

Berdasarkan tabel 3 hasil analisis kadar flavonoid pada ekstrak getah angsana di Dusun Wanath yang diperoleh yaitu pada pengulangan I sebesar 0,0429\% dan pada pengulangan II sebesar 0,0439\%. Hal ini membuktikan hasil yang diperoleh antara kedua pengulangan untuk menentukan kadar flavonoid pada ekstrak getah angsana tersebut tidaklah jauh berbeda. Sedangkan rata-rata kadar flavonoid berdasarkan dari kedua kadar flavonoid yang didapat tersebut, maka ratarata kadar flavonoidnya yaitu sebesar 0,0434\%.

\section{Uji Warna Flavonoid}

Berdasarkan hasil identifikasi flavonoid secara kualitatif dengan menggunakan metode mikrokimiawi (uji warna) diketahui bahwa ekstrak getah angsana yang memiliki warna awal merah kemudian ditambahkan dengan aquades warnanya menjadi jernih sehingga hasil ujinya memiliki tanda negative yang artinya bahwa tidak terdapat flavonoid pada pereaksi tersebut. Sebaliknya dengan mengunakan pereaksi $\mathrm{NH}_{4} \mathrm{OH}, \mathrm{NaOH}$, dan $\mathrm{AlCl}_{3}$, terjadi perubahan warna pada masing-masing tabung reaksi dari warna awal merah berubah menjadi kuning sehingga hasil ujinya memiliki tanda positif, hal ini menunjukan bahwa terdapatnya flavonoid jika dipereaksikan pada pereaksi flavonoid tersebut.

Aquades bertindak sebagai control negatif dimana hasil perlakuannya yaitu larutan tersebut akan menjadi jernih menandakan bahwa tidak ada flavonoid (Mutiara dan Wildan, 2014). Pereaksi yang sering digunakan untuk identifikasi flavonoid sebagai pereaksi adalah amoniak $\left(\mathrm{NH}_{4} \mathrm{OH}\right)$, $\mathrm{NaOH}, \mathrm{AlCl}_{3}$, sitroborat akan memberikan warna kuning (Robinson, 2000). Uji senyawa flavonoid dinyatakan positif mengandung flavonoid jika reaksi yang terjadi menghasilkan perubahan warna merah, kuning, atau orange pada lapisan amil alkohol (Harbone 1987).

\section{Uji Kadar Flavonoid}

Penentuan kadar flavonoid dilakukan dengan metode spektofotometri. Spektofotometri serapan ultraviolet dan serapan sinar tampak merupakan cara 
tunggal yang paling berguna untuk menganalisis flavonoid (Markham, 1988). Kuersetin digunakan sebagai baku standar dan sebagai kurva kalibrasi, pada spektofotometri UV-Vis dengan panjang gelombang $370 \mathrm{~nm}$.

Pemeriksaan kadar flavonoid total dalam sampel terlebih dahulu dibuat kurva baku larutan standar kuersetin terhadap absorbansi. Diperoleh persamaan regresi $Y=0,0533 x+0,0051$ dan harga koefisien korelasi (r) yaitu 0,9997. Berdasarkan persamaan regresi tersebut, dilakukan perhitungan kadar flavonoid total pada setiap sampel dengan dua kali pengulangan, diperoleh presentasi pada pengulangan pertama menghasilkan kadar flavonoid sebesar 0,0429\% sedangakan pada pengulangan kedua menghasilkan kadar flavonoid sebesar $0,0439 \%$. Dengan rata-rata kadar flavonoid pada kedua pengulagan tersebut adalah sebesar $0,0434 \%$. Hasil analisis kadar flavonoid ekstrak getah angsana tersaji pada tabel 3 terlihat bahwa terdapat dua pengulangan dengan berat sampel, absorbansi, dan konsentrasi yang berbeda sehingan terdapat perbedaan pada kadar flavonoidnya.

Fungsi dari pereaksi $\mathrm{AlCl}_{3}$ adalah untuk memebentuk reaksi antara $\mathrm{AlCl}_{3}$ dengan golongan flavonoid memebentuk kompleks antara gugus hidroksil dan keton yang bertetangga atau dengan gugus hidroksil yang saling bertetangga. $\mathrm{AICl}_{3}$ akan bereaksi dengan gugus keton pada $\mathrm{C} 4$ dan gugus $\mathrm{OH}$ pada $\mathrm{C} 3$ atau C5 pada senyawa flavon atau flavonol membentuk senyawa kompleks yang stabil berwarna kuning. Senyawa yang digunakan sebagai standar pada penetapan kadar flavonoid ini adalah kuersetin, karena kuersetin merupakan flavonoid golongan flavonol yang memiliki gugus keto pada atom C-4 dan juga gugus hidroksil pada atom C-3 dan C-5 yang bertetangga (Sari, 2017).

Senyawa flavonoid adalah golongan senyawa yang tidak tahan panas dan mudah teroksidasi pada suhu tinggi (Hasan dan Laily, 2014). Suhu yang tinggi dapat merusak flavonoid (Inggrid dan Santoso, 2014). Disebabkan karena flavonoid yang berbentuk glikosida terhindrosida menjadi aglikon. Hidrolisis glikosida antosianin dalam dalam kondisi asam menghasilkan aglikon antosianidin (Sadilova dkk, 2006).

\section{KESIMPULAN}

Berdasarkan hasil penelitian, maka dapat disimpulkan bahwa: Uji kualitatif (uji warna) ekstrak getah angsana positif mengandung flavonoid ketika di identifikasi dengan beberapa pereaksi flavonoid yaitu menghasilkan warna kuning.

\section{DAFTAR PUSTAKA}

Badan POM, (2006). Pedoman Cara Pembuatan Obat yang Baik. Jakarta: BPOM.

Chang, C.C., Yang., M.H., Wem, H.M., Chern, J.C., 2002, Estimation of Total Flavonoid Content in Propolis by Two Comlpementary Colorimetric Methods, Journal of Food and Drug Analysis, Vol. 10, No.3, 2002. Pages 178-182.

Dalimarta S. 2000. Atlas Tumbuhan Obat Indonesia. Bogor: Trubu Agriwidya

Harbone JB. 1987. Metode Fitokimia Penuntun Cara Modern Menganalisa Tumbuhan Ed ke-3. Bandung (ID): ITB

Haris, M. 2011. Penentuan Kadar Flavonoid Total dan Aktivitas Antioksidan dari Daun Beluntas (Plucea indica L). FMIPA UNSRAT Manado 95115.

Hasan, N.M dan Laily, N.A. 2014.Uji Kandungan Flavonoid dan Perbandingan

Aktivitas Antioksidan Pada Ekstrak Etanol Simplisia Bunga Pepaya Gantung Saat Kuncup dan Mekar.Biologi Saintek UIN Maliki Malang.

Inggrid, M., Santoso, H. 2014.Ekstraksi Antioksidan dan Senyawa Aktif dari Buah Kiwi (Actinidia deliciosa), Perjanjian No: III/LPPM/2014-03/10-P, Universitas Katolik Parahyangan: Bandung.

Kurniasari, I. 2006. Metode Cepat Penentuan Flavanoid Total Meniran (Phyllantus niruri L) Berbasis Teknik Spektrofotometri Inframerah Dan Kemometrik.IPB, Bogor.

Markham, K.R., 1988, Cara Mengidentifikasi Flavonoid, diterjemahkan oleh Kosasih Padmawinata, 15, Penerbit ITB, Bandung. 
Mulyani, Sri dan Toga Laksana. 2011. Analisis Flavonoid dan Tannin dengan Metode Mikroskopi-Mikrokimiawi. Biologi Farmasi UGM: Yogyakarta.

Mutiara, V.E dan Wildan, A. 2014.Ekstraksi Flavonoid Dari Daun Pare (Momordica charantia L.) Berbantu Gelombang Mikro Sebagai Penurun Kadar Glukosa Secara in Vitro. Sekolah Tinggi IImu Farmasi. Vol. 10 No. 01, Juli 2014, Hal. 1-11

Neldawati, dkk. 2013. Analisis Nilai Absorbansi Dalam Penentuan Kadar Flavonoid untuk Berbagai Jenis Daun Tanaman Obat. FMIPA Universitas Padang.

Redha. A. 2010. Flavonoid: Struktur, Sifat Antioktidatif dan Peranannya Dalam Sistem Biologi. Teknologi Pertanian Politeknik Pontianak. Vol. 9 No. 2: 196:202.

Robinson, T. 2000. Kandungan Organik Tumbuhan Tinggi Penerbit ITB. Bandung

Sani, N.N., Nisfi Nahari., Markus Diantoro.2014. Pengaruh Perak Pada Film Flavonoid Berbahan Dasar Getah Pohon Angsana (Pterocarpus indicus Willd) Terhadap Kristalinitas dan Konduktivitas Listrik. Skripsi, Jurusan Fisika, Fakultas MIPA, Universitas Negeri Malang.

Sari, K.A. 2017.Penetapan Kadar Fenolik Total dan Flavonoid Total Ekstrak Beras Hitam (Oryza sativa L.) dari Kalimantan Selatan. Jurnal IImiah Ibnu Sina, 2 (2), 327-335.

Sadilova, E., Stintzing, E.C. dan Carle, R. (2006). Thermal degradation of acylated and nonacylated anthocyanins. Journal of Food Scince 71: C504-C512.

Wijayakusuma H., 2008. Ramuan Lengkap Herbal Taklukkan Penyakit. Jakarta: Pustaka Bunda. 